\title{
ANNOUNCEMENT
}

\section{FOURTH EDITION OF THE INTERNATIONAL CODE OF ZOOLOGICAL NOMENCLATURE}

A Discussion Draft of a new (fourth) edition of the Code is now available. Copies are being sent without charge to all subscribers to the Bulletin and to members of the American and European Associations for Zoological Nomenclature. Any other institution or individual may order a copy from the Executive Secretary, I.C.Z.N., \% The Natural History Museum, Cromwell Road, London SW7 $5 \mathrm{BD}$. The cost of printing and postage is about $£ 3$ or US\$5. Bank charges on currency exchange make it uneconomic to pay this amount except in sterling or US dollars. The draft of the Code will therefore be sent free of charge, but those able to pay in sterling or US dollars are asked to enclose a cheque for $£ 3$ or US\$5 to cover the cost.

Before completing the definitive text of the Fourth Edition, the Commission will (in accordance with Article 16 of its Constitution) take into account all comments and suggestions on the draft submitted within one year of its original distribution.

TOWARDS STABILITY IN THE NAMES OF ANIMALS

The International Commission on Zoological Nomenclature was founded on 18 September, 1895. In recognition of its Centenary a history of the development of nomenclature since the 18th century and of the Commission has been published entitled "Towards Stability in the Names of Animals- a History of the International Commission on Zoological Nomenclature 1895-1995" (ISBN 085301 $0056)$. It is 104 pages $(250 \times 174 \mathrm{~mm})$ with 18 full-page illustrations, 14 being of eminent zoologists who played a crucial part in the evolution of the system of animal nomenclature as universally accepted today. The book contains a list of all the Commissioners from 1895 to the present. The main text was written by R. V. Melville (former Secretary of the Commission) and has been completed and updated following his death.

Copies may be ordered from I.T.Z.N., $\%$ The Natural History Museum, Cromwell Road, London SW7 5BD, U.K. or A.A.Z.N., \% NHB Stop 163, National Museum of Natural History, Washington, D.C. 20560 , U.S.A. The cost is $£ 30$ or $\$ 50$ (including surface postage); members of the American and European Associations for Zoological Nomenclature are offered the reduced price of $£ 20$ or $\$ 35$. Payment should accompany orders. 